\title{
A Teacher Accountability Model for Overcoming Self-Exclusion of Pupils
}

\author{
Abu-Hussain Jamal ${ }^{1}$, Oleg Tilchin ${ }^{1} \&$ Mohammad Essawi $^{1}$ \\ ${ }^{1}$ Al-Qasemi Academic College of Education, Baqa El-Gharbieh, Israel \\ Correspondence: Oleg Tilchin, Computer Science Department, Academic College of Education P.O. Box 124, \\ Baqa El-Gharbieh 30100, Israel. E-mail: otilchyn@yahoo.com
}

\author{
Received: March 14, 2015 Accepted: April 20, 2015 Online Published: August 26, 2015 \\ doi:10.5539/ies.v8n9p58 URL: http://dx.doi.org/10.5539/ies.v8n9p58
}

\begin{abstract}
Self-exclusion of pupils is one of the prominent challenges of education. In this paper we propose the TERA model, which shapes the process of creating formative accountability of teachers to overcome the self-exclusion of pupils. Development of the model includes elaboration and integration of interconnected model components. The TERA model involves the following components: Tasks, Environment, Reward, and Accountability. The "Task" component serves as the starting point for creating teacher accountability. The objective of the Task" component is to form a structure of tasks, performance of which leads to overcoming self-exclusion of pupils. The task structure allows determining task significance for pupils' inclusion. The "Environment" component organizes an environment inducing the teachers toward productive and qualitative performance of the tasks directed toward overcoming self-exclusion of pupils. Such an environment fosters creating teacher reciprocal accountability for task performance results. The environment is organized by the conditions of adaptive performance of the tasks and adaptive rewarding of teachers. "Accountability" is the central component of the model. The objective of this component is to create formative accountability of teachers for task performance results. It is attained through self-assessment willingness, possibility, and desire of teachers to be emergent leaders or performers during tasks performance, and coordination of the self-assessment outcomes. The objective of the "Reward" component is to realize adaptive rewarding of teachers for taking accountability for task performance results. Adaptation of rewards is provided relative to task significance and a teacher's role in a task's performance.
\end{abstract}

Keywords: self-exclusion of pupils, teacher accountability

\section{Introduction}

Self-exclusion of pupils is a complicated multidimensional challenge of education. This challenge is influenced by numerous factors. Some of these factors are poor acquisition of basic skills, limited aspirations and opportunities, poverty, family difficulties, poor relationships with other pupils, parents or teachers, or pressure from other pupils (Kyriacou, 2003). The challenges' solution requires a complex approach. Such approach intends unfolding actions leading to overcoming self-exclusion of pupils and their subsequent and conformed realizations. The basic actions that can lead to overcoming self-exclusion of pupils are effective teaching, effective learning, formative assessment for learning, productive self-evaluation of a school, successful leadership (Ainscow, Dyson, \& Weiner, 2013). Most from these actions should be realized by teachers. Hence, the role of a teacher in overcoming self-exclusion of pupils is decisive.

The successful realization of the actions leading to overcoming the self-exclusion of pupils requires creating a conducive school environment. A school environment is engendered by a school culture which determines how teachers think, feel, and act (Connors \& Smith, 2011). A school culture influences commitment, motivation, and productivity of teachers to encourage conversions of teacher's attitude toward pupils from object to subject. A successful school culture is based on "core values of collegiality, performance, and improvement that engender quality, achievement, and learning for everyone" (Deal \& Peterson, 2009). Compliance with the core values is supported by leadership, cultivating an accountability culture in a school (Samuel, 2001).

An accountability culture should inspire accountability through creating and sustaining purposefulness, fulfillment, and motivation of teachers, and by building trust and collaboration among them (Worral, 2013; Bustin, 2014). The accountability culture promotes greater performance, and higher quality is characterized by 
the presence of teachers who serve as emergent leaders of teacher groups, with trustworthy communications between these teachers and principals (Chrispeels, 2004; Frost \& Durrant, 2004; Harris \& Muijs, 2004; Worral, 2013). The group members hold themselves mutually accountable for outcomes (Katzenbach \& Smith, 2006). The emergent leader takes accountability for the results of the actions of the group (Harris \& Muijs, 2004; Browning, 2012).

Formation of accountability culture in a school which engenders an environment promoting inclusion of pupils means, first of all, creating teacher accountability for results from the performance of the needed actions. A model for the creation of formative accountability of teachers for overcoming self-exclusion of pupils is proposed in this paper.

\section{Literature Review}

Research of different aspects of forming an accountability culture in a school which promotes overcoming self-exclusion of pupils is examined.

Brundrett and Rhodes (2011) declare that high-quality teaching and learning can be attained by leadership allowing development of a culture of quality through creation of accountability. Following Evans (2008), success of a school requires including accountability into its strategy, determining clear expectations, and creating relationships among teachers based on accountability. Owing to this, job satisfaction and school performance are improved.

Rick (2003) affirms that building school accountability culture is possible through the sharing of leadership owing to commitment to ideas, not personalities. As a result of this, a principal has an obligation to support teachers and the goals of the school. Students have an obligation to learn, teachers to teach, and parents to support learning. Harris and Muijs (2004) confirm that sharing accountability through sharing leadership leads to school improvement. The authors describe emergent features and restricted teacher leadership.

Gilbert (2012) asserts that creating a culture of reciprocal accountability is one of the most significant elements in providing school performance improvement. According to the author, it requires: changing school culture so that accountability turns toward a cultural value of teachers; integrating formative and summative accountability; organizing peer collaboration that develops the work of teachers and the learning of students. Grimshaw and Baron (2010) suggest the three conditions of providing accountability. The conditions are: to communicate distinct requirements for performance to teachers; to create a structure of influence that can provide desired performance; and to lead discussion among teachers directed towards the coordination of possibilities. According to Frink and Kimosky (2004), teachers play different roles in their interdependent work to attain school results. Hence, accountability of teachers should depend on their roles. The authors offer using role theory as a framework for accountability.

Samuel (2001) offers a systematic approach to increasing personal and organizational accountability. The approach includes the leadership strategy directed towards development of the accountability culture and accountability culture elements. The leadership strategy involves creating a clear direction of organizational activity; building a plan that guarantees the result; communicating and executing to realize high performance, and developing teachers to be highly accountable performers. The accountability culture elements are: clear intention to attain the desired result; effective execution caused by interdependence, coordination, communication; the actions of the teachers necessary to attain the desired result; responsive recovery; the measuring of results to provide good performance, and rewarding.

Abu-Hussain, Essawi, and Tilchin (2014a) have developed an approach to building result-based accountability in an organization through the forming of an accountability structure and conformed self-assessment of an employee's willingness and desire to take accountability for delivering the results. According to an approach of Connors and Smith (2011), creation of accountability culture in a school is a result of consecutive realization of the steps conducive to teacher accountability. These steps are: see it, own it, solve it, and do it. Essawi and Tilchin (2013) suggested a constructive confrontation approach to managing organizational culture. The approach allows forming a constructive confrontation environment in a school which promotes the creation of accountability of teachers for changing their cultural values according to the required organizational values.

An approach of Abu-Hussain, Essawi, and Tilchin (2014b) focuses on creation of accountability for learning results. For this, the specific Project-Based Collaborative Learning (PBCL) model was built. The model shapes a process of creating accountability for learning results, with specific formation of a collaborative group of pupils, and the design of a flexible assessment system. Personal accountabilities of pupils are created by self-assessments. A collaborative group is formed as a result of the coordination of personal accountabilities of 
pupils, for performance of a determined project task, and securing their reciprocal accountability in the performance of a group project.

Samuel and Chiche (2004) describe the personal accountability model, furthering realization of the intention to stay accountable. The model is based on determining accountability as action that is consistent with the desired outcomes of a teacher. The model components are: recognize, own, forgive, self-examine, learn, and take action. Jones (2004) suggests adjusting school accountability models from business with a focus on student learning. Bergsteiner (2012) designed a decision tree model for the building of goal-oriented accountability, and a Holistic Accountability Model that can be used for shaping mutual influence and behaviors of teachers in the accountability process.

The analysis of the above publications shows that the challenges connected with creating teacher accountability to overcome self-exclusion of pupils remain. The specific structure of tasks directed towards overcoming self-exclusion of pupils is not presented. Such a task structure can serve as a basis for creating proper accountability of teachers through unfolding task significance in attaining desired goals and skills needed for task performance. A school environment that fosters the creation of accountability of teachers for the performance of required tasks is not formed. The conditions of adaptive performance and adaptive rewarding are not determined. A mechanism of sharing of accountability of teachers on the basis of a choice of a suitable role in task performance is absent. A balance between competition and collaboration among teachers to receive results of task performance has not been secured. Rewarding teachers has not been connected with accountability for results of the performance of corresponding tasks on the basis of the tasks' significance and roles chosen by teachers in this process.

\section{A Teacher Accountability Model for Overcoming Self-Exclusion of Pupils}

The purpose of developing a dynamic model is to shape the process of creating teacher accountability to overcome self-exclusion of pupils. Development of the model includes elaboration and integration of interconnected model components. Dynamics of the model are provided by the change of its parameters, and they express the dynamic process of creating teacher accountability for inclusion of pupils. The TERA model involves the following components: Tasks, Environment, Reward, Accountability (Figure 1).

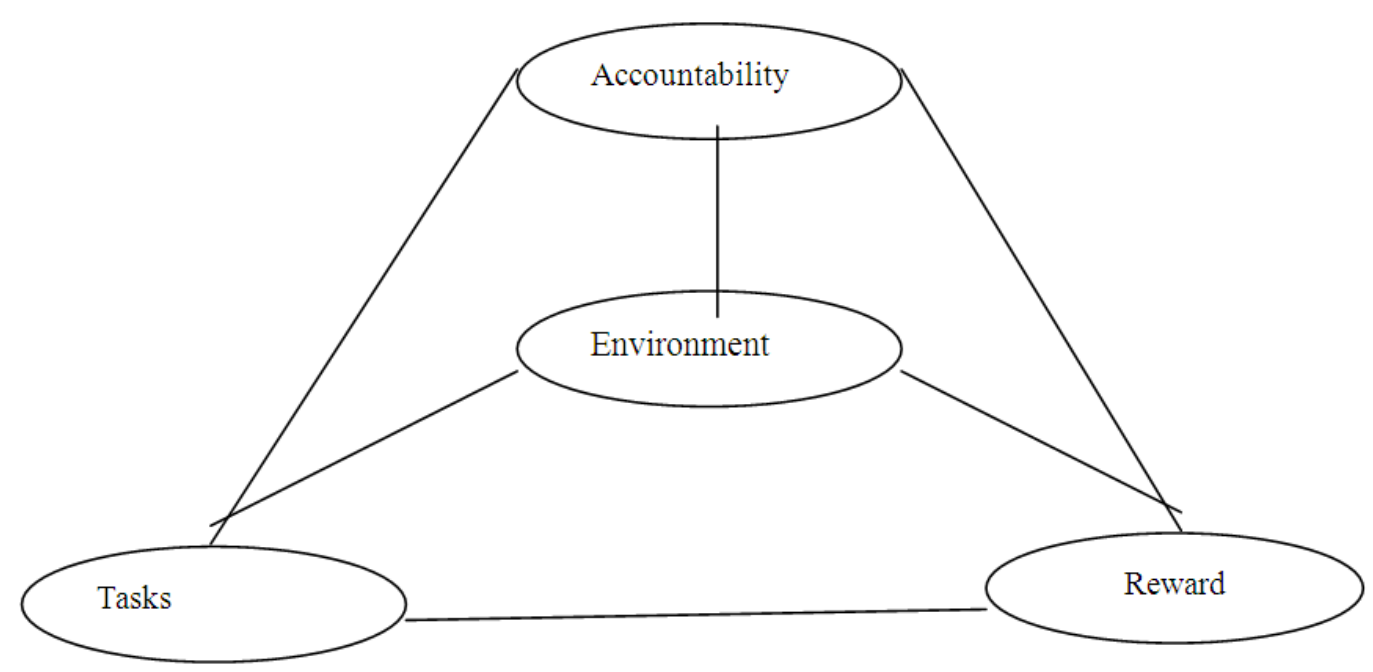

Figure 1. The TERA model

\section{The "Task" Component}

The objective of the "Task" component is to form a set of interconnected tasks, performance of which leads to overcoming self-exclusion of pupils. The "Task" component serves as the starting point for creating productive accountability culture in a school.

The procedures for the "Task" component realized by a principal are:

- Determining a school activity goal. The goal is overcoming self-exclusion of pupils through creation of teacher accountability. 
- Developing the actions and sequence for their realization leading to the goal. Each action is characterized by a significance level with regard to attaining the goal.

- $\quad$ Forming a set of tasks realizing the actions, and building a task structure. The task structure is a result of interconnection of tasks expressing task performance order. Task-relevant skills correspond to each task. The task-relevant skills are skills needed for task performance. Each task is characterized by its significance as it concerns overcoming self-exclusion of pupils. Significance of a task is the sum of a significance level of an action to which a task belongs, and a task's structural significance. Structural significance of a task is the sum of significance levels of actions, of which descendants of a task belong.

Example 1: A structure of the tasks, the performance of which leads to the desired goal, is represented by Figure 1. The actions, the significance levels of the actions, the interrelated tasks realizing the corresponding actions, task-relevant knowledge, and significance of the tasks are shown by Figure 1. The order of task performance is shown with arrows. The performance result of the task $z_{6}$ is the final result of the task structure.

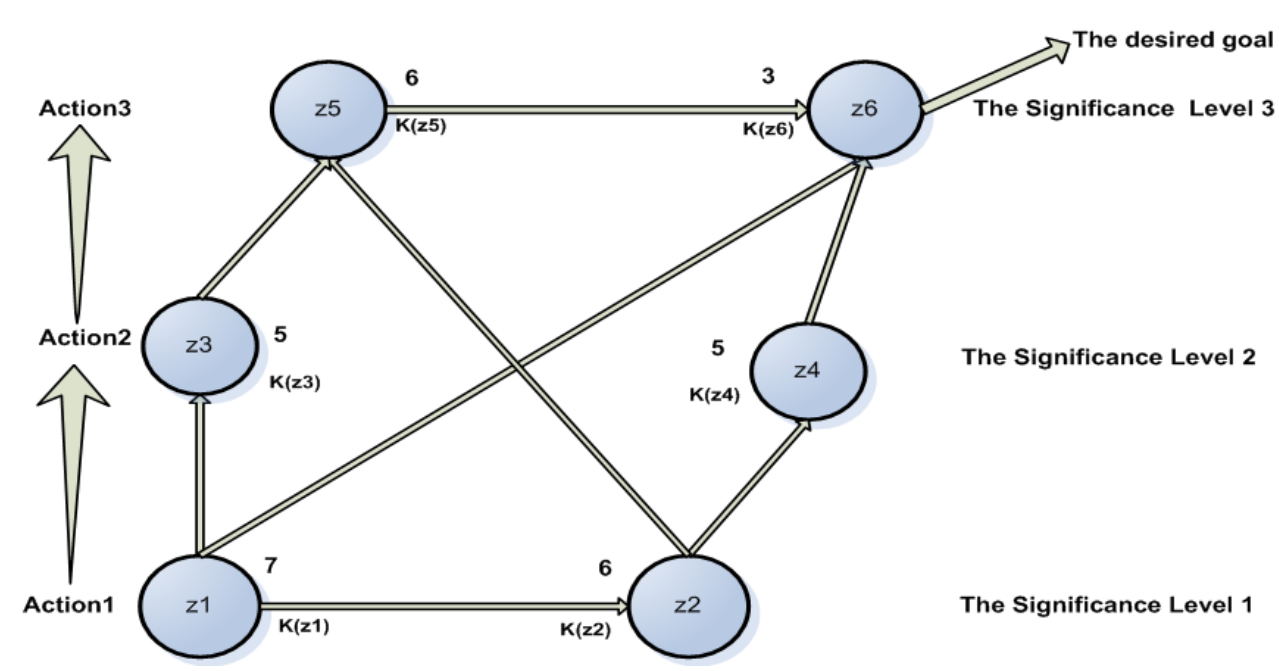

Figure 2. A task structure

Structural significance of the task $z_{1}$ equals 6 , since it has three successors: the tasks $z_{2}, z_{3}$, and $z_{6}$. The significance levels of the task's successors are $1,2,3$, accordingly. Then significance of the task $z_{1}$ equals 7 , since the task corresponds with the action of first significance level, and its structural significance is 6 .

The "Environment" Component

The objective of the" Environment" component is the organization of a suitable environment in a school. Such environment fosters creation of teacher reciprocal accountability for performance of the tasks needed to overcome self-exclusion of pupils. It induces the teachers towards productive and qualitative performance of these tasks.

The procedures for the "Environment" component realized by a principal are: declaration of the task structure and manifestation of the conditions of the tasks' performance and adaptive reward for overcoming self-exclusion of pupils. The conditions of the tasks' performance include:

- All tasks for overcoming self-exclusion of pupils should be performed. It predetermines full inclusion of pupils.

- All teachers should participate in performance of the tasks. It engenders teachers' reciprocal accountability and the need to collaborate during task performance.

- Skills of a teacher group representing determined course direction should be maximum approximate to a task's relevant skills. It characterizes teachers' willingness for task performance and causes qualitative performance of a task.

- The teachers should choose roles in performance of the tasks. The possible roles are a performer (P) and an emergent leader (L). The performer role requires the presence of needed skills corresponding to 
task-relevant skills. A performer should take accountability for performance of a task piece. The emergent leader role requires the presence of coordination and decision-making skills as task-relevant skills. The leader should take accountability for the final result of a task's performance.

- The quantity of the tasks for the performance of which a teacher may be an emergent leader is limited. It allows productive performance of tasks since it restricts the choice made by a teacher through a task for performance which he (she) has the most willingness and possibility to be a leader.

These conditions secure adaptive performance of the tasks, attained by taking into account task-relevant skills and choice of a suitable role in task performance.

Manifestation of the conditions of adaptive reward which induce the desire of the teacher to take accountability for a task's performance results. These conditions include:

- All teachers are rewarded. It motivates the teacher to take accountability for results of task performance.

- The teachers receive greater reward for taking accountability for the more significant task. It provides for the adaptation of rewarding to task significance.

- A task leader receives an appreciably greater reward then a task performer. It provides adaptation of rewards to teacher roles in task performance.

The "Accountability" Component

The objective of the "Accountability" component is creating accountability of teachers for task performance results. "Accountability" is the central component of the model.

The procedures for the "Accountability" component realized by teachers and the principal are:

- Choice of the tasks for results performance of which a teacher group corresponding with determined course would be accountable. The choice is carried out through group self-assessment, its willingness, possibility, and desire to perform the tasks. Group self-assessment is realized by examination of the task structure engendered by the "Task" component and the conditions of adaptive performance and adaptive reward (the "Environment" component).

- Adjustment of group choices. This procedure is realized through discussion of groups with participation of the principal. During discussion, the tasks chosen by the groups are compared. The aim of comparison is agreement on the group choices. Owing to this, initial group choices can be changed.

- Choice of roles in task performance by teachers. This procedure is realized by teacher self-assessment. During self-assessment, a teacher compares his (her) skills with task-relevant skills. The willingness of a teacher to be task-leader is caused by availability of coordination and decision-making skills, together with skills needed for performance of the chosen task.

The willingness of a teacher to be the performer of a task piece is caused by availability of skills relevant to the task piece skills. As a result of self-assessment, a teacher expresses a sound desire to be accountable personally for the final result of a task performance (i.e. to be task-leader), or to share accountability for the task performance result (i.e. to be a task-performer) with other teachers. Self-assessments of teachers allow for attaining a balance between competition and collaboration among teachers. If a teacher doesn't have required skills or desire to be a task-leader, he (she) doesn't compete with peers, but makes a decision to collaborate during performance of a task. If a teacher has needed skills and desires to be a task-leader, he (she) competes with his (her) peers for this role in performance of a task.

Coordination of the self-assessment outcomes to complete the taking of accountability of teachers for the results of the tasks' performance. This procedure is realized through discussion of teachers with participation of a principal. During discussion, every teacher compares tasks for which they would be accountable as a leader with those tasks chosen by peers and the performance for which they would be leaders. The aim of comparison is to coordinate taking personal accountability for final results of the tasks performance and sharing accountability for performance of the task pieces.

The tasks selected earlier by a teacher for performance as a leader can be replaced by other tasks due to coordination with peers. If some teachers want to be leaders who are accountable for the final result of performance of the same task, despite coordination of their outcomes, then the principal will determine the teacher who should be accountable for the result. All tasks should be performed. Hence, if there is not a teacher who shows willingness to take accountability for the final result of a task's performance as a leader, the principal delegates this role to the most suitable teacher. 


\section{The "Reward" Component}

The objective of the " Reward" component is realizing adaptive rewarding of teachers for taking accountability for results of performing of task pieces and the final result of a task's performance, aimed at overcoming pupils' self-exclusion. Rewarding of teachers is realized according to reward conditions (the "Environment" component) The size of rewards for taking accountability for performance results of all tasks, and the size of reward of a task leader are set by a principal. The size of the reward for task performers is divided among them by a task leader.

The procedures for the "Reward" component are:

- Establishment of size of teachers' rewards

- Calculation of teachers' rewards for taking accountability for task performance results according to task significances

- Dividing rewards for taking accountability for a task performance result among teachers according to their roles in a task performance

- Determining total rewarding of the teachers

Example 2: The established size of teachers' rewards for taking accountability for overcoming pupils' self-exclusion equals $\$ 2000$. There are six tasks $z_{1}, z_{2}, \ldots, z_{6}$, performance of which should provide for attainment of this goal. The task significances are 4, 3, 3, 3, 4, 3, accordingly (Figure 1). Then, the established amounts of teachers' rewards for taking accountability for task performance results in corresponding with task significances are $\$ 400, \$ 300, \$ 300, \$ 300, \$ 400, \$ 300$, accordingly.

The predetermined size of reward for taking accountability for the results of performance of tasks is divided among teachers on the basis of their roles in task performance, e.g. task leader receives $80 \%$ and all task performers receive $20 \%$ of the reward. There are five teachers of some course direction. Then, there is one leader and four performers for each task.

Teacher $t_{1}$ is a leader of tasks $z_{1}$ and $z_{2}$, and a performer of other tasks. Then, size of reward of the teacher $t_{1}$ as the task leader is $\$ 560$, and size of reward of this teacher as the task performer is $\$ 65$. Total rewarding of the teacher is $\$ 625$.

\section{Conclusions}

The TERA model adjusts creating teacher accountability for overcoming self-exclusion of pupils by consistent realization of corresponding components. Creating proper accountability of teachers as emergent leaders or performers for results of selected tasks' performance is provided by The "Accountability" component which is the central component of the model. Choice of the tasks by teachers to take accountability for result of their performance is realized through self-evaluation and coordination with peers and the principal. Self-evaluation of willingness, desire, and possibility of teachers to take accountability is based on consideration task structure, task features, and the conditions characterizing environment fostering creation of accountability. Owing to that, reciprocal accountability of teachers and sharing accountability on basis of chosen roles in performance of the tasks are created. It secures a balance between competition and collaboration among teachers for achieving results of a task's performance.

The structure of tasks, performance of which is required for overcoming self-exclusion of pupils, is determined by the "Tasks" component of the model. Task significance and task-relevant skills serve as features of each task. A specific school environment, which is organized by the "Environment" component, promotes effective performance of the tasks by the teachers. The conditions of adaptive performance of the task and adaptive rewarding of teachers for taking accountability for results characterize the environment. Adaptive rewarding relative to task significance and a teacher's role in a task's performance is determined by the "Reward" component.

The TERA model can serve as a constructive tool for overcoming the self-exclusion of pupils. The model is universal. The model can be used for solving a variety of school problems.

\section{References}

Abu-Hussain, J., Essawi, M., \& Tilchin, O. (2014a). Accountability for Project-Based Collaborative Learning. International Journal of Higher Education, 3(1), 127-135. http://dx.doi.org/10.5430/ijhe.v3n1p127

Abu-Hussain, J., Essawi, M., \& Tilchin, O. (2014b). Building Result-Based Accountability in an Organization. Open Journal of Business and Management, 2(3), 195-203. http://dx.doi.org/10.4236/ojbm.2014.23024

Ainscow, M., Dyson, A., \& Weiner, S. (2013). From Exclusion to Inclusion. Centre for Equity in Education, 
University of Manchester. Retrieved from http://cdn.cfbt.com/ /media/cfbtcorporate/files/research/2013/ r-from-exclusion-to-inclusion-2013.pdf

Bergsteiner, H. (2012). Accountability Theory Meets Accountability Practice. Emerald Group Publishing Limited Browning, H. (2012) Accountability: Taking Ownership of Your Responsibility. Pfeiffer (1st ed.).

Brundrett, M., \& Rhodes, C. (2011). Leadership for quality and accountability in education. London \& New York, Routledge.

Bustin, G. (2014). Accountability: The Key to Driving a High-Performance Culture (1st ed.). McGraw-Hill.

Chrispeels, J. H. (2004). Learning from challenge. Aiming toward promise. In J. H. Chrispeels (Ed.), Learning to lead together: The promise and challenge of sharing leadership. Thousand Oaks, CA: Sage. http://dx.doi.org/10.4135/9781452232416.n15

Connors, R., \& Smith, T. (2011). Change the Culture Change the Game. Penguin Group Inc.

Deal, T., \& Peterson, K. (2009). Shaping School Culture: Pitfalls, Paradoxes and Promises (2nd ed.). San Francisco: Jossey-Bass.

Essawi, M., \& Tilchin, O. (2013). A Constructive Confrontation Approach to Managing Organizational Culture. Journal of Business and Management Sciences, Science and Education Publishing, 1(4), 71-76.

Evans, H. J. (2008). Winning with Accountability: The Secret Language of High-Performing Organizations. Corner Stone Leadership Institute

Frink, D. D., \& Kimoski, R. J. (2004). Advancing Accountability. Theory and Practice. Introduction to the Human Resource Management, Human Resource Management Review, 14(1), 1-17. http://dx.doi.org/10.1016/j.hrmr.2004.02.001

Frost, D., \& Durrant, J. (2004). Supporting teachers' leadership: What can principals do? A teachers' perspective from research. In J. H. Chrispeels (Ed.), Learning to lead together: The promise and challenge of shared leadership. Thousand Oaks, CA: Sage. http://dx.doi.org/10.4135/9781452232416.n12

Gilbert, C. (2012). Towards a self-improving system: the role of school accountability. National College for School Leadership. Retrieved from http://dera.ioe.ac.uk/14919/1/towards-a-self-improving-system-schoolaccountability-thinkpiece $\% 5 \mathrm{~B} 1 \% 5 \mathrm{D} . \mathrm{pdf}$

Grimshaw, J., \& Baron, G. (2010). Leadership without Excuses: How to Create Accountability and High Performance (Instead of Just Talking about It). McGraw-Hill.

Harris, A., \& Muijs, D. (2004). Improving Schools through Teacher Leadership (1st ed.). Open University Press.

Jones, K. (2004). A balanced school accountability model: An alternative to high-stakes testing [Electronic version]. Phi Delta Kappan, 85(8), 584-590. http://dx.doi.org/10.1177/003172170408500805

Katzenbach, J. R., \& Smith, D. K. (2006). The Wisdom of Teams: Creating the High-Performance Organization (Collins Business Essentials). Harper Business; Reprint edition to Strengthen Productivity Through Sound Managerial Leadership, The Career Press Inc.

Kyriacou, C. (2003). Helping Troubled Pupils. Cheltenham, Nelson Thornes.

Rick, A. (2003). Building School Culture in an Age of Accountability. Education Update, 45(7). Retrieved from

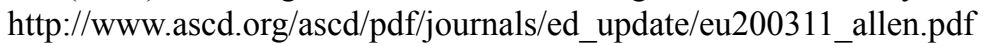

Samuel, M. (2001). The Accountability Revolution: Achieve Breakthrough Results in Half the Time (2nd ed.). Facts on Demand Press.

Samuel, M., \& Chiche, S. (2004). The Power of Personal Accountability: Achieve What Matters to You (1st ed.). Xephor Press.

Worral, D. (2013). Accountability Leadership: How Great Leaders Build a High Performance Culture of Accountability and Responsibility (1st ed.). Worrall \& Associates.

\section{Copyrights}

Copyright for this article is retained by the author(s), with first publication rights granted to the journal.

This is an open-access article distributed under the terms and conditions of the Creative Commons Attribution license (http://creativecommons.org/licenses/by/3.0/). 